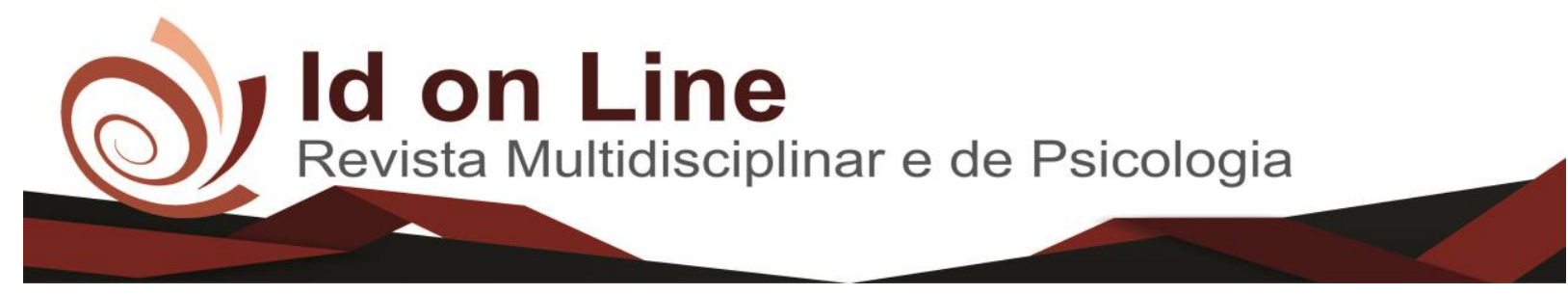

Comment

\title{
Educação Especial na perspectiva da Educação Inclusiva para Surdos
}

\author{
Maria Katariny Cardoso dos Santos ${ }^{1}$; Aurelania Maria de Carvalho Menezes ${ }^{2}$
}

Resumo: Este artigo apresenta dados de estudos bibliográficos relacionadas à inclusão de alunos surdos principalmente no ensino regular. Como embasamento teórico foram analisados diversos fatores referentes às políticas públicas de inclusão do deficiente físico assim como leis específicas inerentes à surdez. Desatacaram-se conquistas, assim com as dificuldades e os desafios que os profissionais da escola inclusiva precisam enfrentar para vencer. Verificou-se que a inclusão está acontecendo, não no ritmo desejado, mas acontece. Constatou-se a importância do intérprete de Libras e seu papel de fidelidade, ética e compromisso que deve ser adotado com seu aluno surdo. Foi apresentada a importância do AEE (Atendimento Educacional Especializado), de trabalhar em união com o ensino regular na educação dos surdos. Muitos teóricos contribuíram para a construção deste trabalho, entre eles destacam-se, Aranha, Góes, Brito e Quadros. As leis que priorizam o atendimento às pessoas com deficiências também mereceram o devido destaque.

Palavras Chaves: Surdez, Ensino Regular, Intérprete, Atendimento Educacional Especializado.

\section{Special Education in the perspective of Inclusive Education for the Deaf}

\begin{abstract}
This article presents data from bibliographic studies related to the inclusion of deaf students mainly in regular education. As a theoretical basis, a number of factors were analyzed concerning the public policies of inclusion of the physically handicapped as well as specific laws related to deafness. Achievements were unleashed, as well as the difficulties and challenges that inclusive school professionals have to face in order to win. It has been found that inclusion is happening, not at the desired pace, but it does happen. The importance of the interpreter of Libras and his role of fidelity, ethics and commitment that should be adopted with his deaf student was verified. It was presented the importance of the ESA (Specialized Educational Assistance), to work in union with the regular education in the education of the deaf. Many theorists contributed to the construction of this work, among them stand out, Aranha, Góes, Brito and Quadros. Laws that prioritize care for people with disabilities also deserved prominence.
\end{abstract}

Keywords: Deafness, Regular Education, Interpreter, Specialized Educational Assistance.

\section{Introdução}

Não tem sido fácil para as famílias e instituições escolares lidar com a perspectiva da inclusão e torná-la uma realidade. Pais se angustiam com as negativas e escolas não conseguem

\footnotetext{
${ }^{1}$ Graduanda do Curso de Licenciatura em Pedagogia pela Faculdade de Ciências Humanas do Sertão Central - FACHUSC. 2017; Contato: katarinykaty@hotmail.com

${ }^{2}$ Graduação em Pedagogia - AEDS. Professora da Escola Municipal Valdemar Soares de Menezes. Professora da FACHUSC - Faculdade de Ciências Humanas do Sertão Central.
} 
atender a demanda devido a inúmeros fatores, como falta de profissional capacitado para atender determinadas deficiências ou espaço físico adequado.

A educação acompanha a história da humanidade e vem passando a cada período por grandes mudanças que requer um novo perfil de homem e de profissional. Entende-se que um professor quando bem formado, tanto a nível inicial ou contínuo, seja cada vez mais, capaz de entender satisfatoriamente a demanda social contemporânea.

Diante dos muitos problemas existentes no âmbito da educação inclusiva, questiona-se, como trabalhar a inclusão da pessoa surda na perspectiva da educação especial? Pois não é fácil colocar a inclusão em prática, pois os alunos com necessidades especiais merecem uma atenção dobrada. Este trabalho aborda as dificuldades que o educando surdo encontra em relação à inclusão escolar.

Trabalhar com a inclusão é trabalhar para a igualdade, mas a realidade é outra, pois as crianças da educação especial não acompanham os colegas da classe, o ideal, seria ter um apoio especializado para melhores resultados.

São muitos os objetivos que nortearam este trabalho, como: perceber se as pessoas com deficiência auditiva têm acesso a um sistema educacional inclusivo em todos os níveis, identificar se há uma cultura de convivência com as diferenças e as exigências legais da Educação Inclusiva, analisar os suportes pedagógicos e técnicos inerentes à Educação Inclusiva do indivíduo surdo, compreender o papel do intérprete e averiguar o funcionamento das salas de AEE - Atendimento Educacional Especializado.

Focalizou-se a inclusão do aluno surdo, pois esses sujeitos precisam estar incluídos formalmente em escolas de ensino regular. A trajetória percorrida para alcançar direitos legais na educação de surdos tem sido árdua e trabalhosa. No entanto, existem conquistas que tornam mais fácil o ensino e a aprendizagem do deficiente auditivo, como é o caso das salas AEE Atendimento Educacional Especializado, que fornecem no contra turno o ensino da sua língua materna, a LIBRAS - Língua Brasileira de Sinais, para que o aluno tenha condições de estruturar seu pensamento, fazendo uso dessa língua, interagindo com colegas, educadores e, tornar-se apto para construir outros conhecimentos inclusive na língua portuguesa, sua segunda língua, sendo este, um desafio, pois a maior dificuldade para o aluno surdo é aprender a língua escrita.

Muitos estudos foram realizados para o embasamento teórico do referido trabalho, por tanto, tem natureza bibliográfica e qualitativa. A pesquisa aconteceu através livros, revistas periódicas, em artigos científicos publicados na internet, em monografias e dissertações 
encontradas no acervo da Biblioteca da instituição Faculdade de Ciências Humanas do Sertão Central - FACHUSC. Destacam-se nesta obra profissionais como Aranha (2004), Góes (1996), Sanches e Teodoro (2006) e outros.

Esse trabalho de conclusão de curso foi dividido em temas co-relacionados. Abordouse a Educação Especial e a inclusão, como decisivos para uma sociedade mais justa. Falou sobre a inclusão do aluno surdo nas salas de educação regular e apresentando a importância das salas de AEE como recurso de ensino e aprendizagem no contra turno. Apresentou também a importância de um intérprete para o aluno surdo e os benefícios provenientes da ajuda desse profissional.

\section{Esducação Especial e Inclusão}

Os professores devem está atentos às novas expectativas relacionadas ao ensino e aprendizagem dos alunos com deficiências, pois vivem diariamente com essa dificuldade de trabalhar com sujeitos com necessidades especiais e este deve está devidamente matriculado e frequentando diariamente a sala de ensino regular.

De acordo com a Constituição Federal de 1988 houve um grande avanço no Brasil, pois o (Art.5) garante o direito a igualdade, tratando também no (Art. 205), o direito de todos à educação e complementa com o (Art. 206) que garante a igualdade de condições, o acesso e a permanência na escola.

A Lei de Diretrizes e Bases da Educação Nacional- LDB (1996) garante o acesso e permanência na escola, mas acrescenta que é obrigação do estado promover o acesso desses educandos, preferencialmente nas escolas da Rede Pública de Ensino. Uma das barreiras no caminho é o fato de que muitos não avaliam a inclusão como uma atualização de seus conhecimentos dando outro significado ao processo de construção do indivíduo entendendo desse modo, a amplitude que envolve o processo inclusivo.

Segundo Pereira (2009)

\footnotetext{
A idéia de uma sociedade inclusiva se fundamenta numa filosofia que reconhece e valoriza a diversidade, como característica inerente à constituição de qualquer sociedade. Partindo desse principio e tendo como horizonte o cenário ético dos Direitos Humanos, sinaliza a necessidade de se garantir o acesso e a participação de todos, a todas as oportunidades, independentemente das peculiaridades de cada indivíduo. (PEREIRA, 2009)
} 
Conforme Pereira, pode-se identificar a inclusão propondo projetos que assegurem o acesso e permanência do aluno especial no ensino regular evitando a exclusão escolar.

Outra etapa importante da inclusão é a acessibilidade, pois a sociedade ainda não se encontra em harmonia com a mesma. Em se tratando de acessibilidade algumas mudanças foram imprescindíveis para os grandes avanços e conquistas atuais, como exemplo na década de 1980, com o aparecimento do movimento pelos direitos das pessoas com necessidades especiais, sinalização em vias públicas ou não, rampas e leis específicas. Mas a construção de um novo tipo de sociedade através de transformações se dá pelo processo de inclusão social em que todos devem ser colaboradores.

Outro aspecto a ser observado é o papel do professor, pois o mesmo é levado a questionamentos pertinentes sobre como trabalhar com crianças que têm necessidades especiais e a sua formação para que possa atendê-los sem prejuízos. Os alunos, independente de qualquer coisa, não vêm para sala de aula sem algum conhecimento prévio, eles trazem consigo uma realidade que não pode ser desconsiderada no processo de ensino aprendizagem, esses conhecimentos faz parte da sua história de vida, a diferença será como o professor fará uso disso para obter seus objetivos e ter uma aula proveitosa.

Para Bueno (1998) é necessário reflexão:

(...) temos que pensar que para que a inclusão se efetue, não basta estar garantido na legislação, mas demanda modificações profundas e importantes no sistema de ensino. Essas mudanças deverão levar em conta o contexto sócio-econômico, além de serem gradativas, planejadas e contínuas para garantir uma educação de ótima qualidade. (BUENO, 1998)

Para ofertar uma educação de qualidade para todos os educandos e as pessoas com necessidades especiais, a escola precisa se articular, capacitar, preparar, e adaptar seus professores para obter melhores resultados, pois a inclusão não é só matricular o aluno com necessidades especiais e colocá-lo em uma classe comum, sem dá ênfase às suas necessidades específicas, mas dá suporte ao professor e a escola para colocar em prática sua ação pedagógica.

Por isso a formação do professor é de fundamental importância para receber esse aluno com necessidades especiais, assim como conhecer suas dificuldades, características, desenvolvimento e seus obstáculos. Para isso, é muito eficaz a importância da família nesse processo. Seguindo Aranha (2004):

A família precisa contar com serviços de avaliação e de atendimento às crianças e adolescentes, de forma que possam freqüentar os espaços comuns da comunidade 
desde o início de suas vidas, juntamente com seus familiares. Quando a família não conta com esses serviços, tende a se fechar e a manter a criança em casa, iniciando um processo de segregação e de exclusão já no contexto familiar (ARANHA, 2004, p.14).

Muitas vezes a falta de informação sobre as necessidades da criança, os recursos e procedimentos, deixam os pais de mãos atadas, pois são dependentes de um determinado serviço e não têm condições para tomar decisões e exigir um atendimento de qualidade. Dessa forma, não sabem o que é de sua responsabilidade, direitos e deveres, deixando agravar situações como a saúde e deixando de acompanhar o desenvolvimento do seu filho, acompanhamento esse muito importante.

Para Gokhale (1980), a família é o centro e será sempre uma influência:

\begin{abstract}
A família não é somente o berço da cultura e a base da sociedade futura, mas é também o centro da vida social (...) A educação bem sucedida da criança na família é que vai servir de apoio à sua criatividade e ao seu comportamento produtivo quando for adulto (...) A família tem sido, é e será a influência mais poderosa para o desenvolvimento da personalidade e do caráter das pessoas. ( GOKHALE (1980)
\end{abstract}

Assim podemos relacionar alguns aspectos importantes entre educação/família/escola em primeiro lugar encontramos na família independente do modelo da mesma, afetividade e segurança, mas também medos, incertezas, rejeições, preconceitos e ate violência, com isso é fundamental que o docente conheça quais dificuldades, planos, medos e anseios da família com as quais estão ligadas e com isso conhecer e respeitar as especificidades de cada um.

\title{
A Inclusão dos Surdos nas Salas de Ensino Regular
}

A Língua Brasileira de Sinais - LIBRAS é a língua materna do deficiente auditivo ou pessoa surda, e é composta por todos os aspectos linguísticos que qualquer língua possui.

A comunidade surda muito lutou pelo reconhecimento da LIBRAS como própria da comunidade e no dia 24 de Abril de 2002, a língua de sinais foi regulamentada no território brasileiro pela Lei $N^{\circ} 10.436$, onde reconhece como meio legal de comunicação e expressão a língua brasileira de sinais - LIBRAS e outros recursos de expressão a ela associados. A Lei foi regulamentada pelo Decreto 5.626 de 22 de Dezembro de 2005.

A Lei $N^{\circ}$. 7.853, de 24 de outubro de 1989 dispõe sobre o apoio às pessoas com deficiência e sua integração social. Em seu Artigo 2º inciso I, alínea "f”, descreve sobre "a 
matrícula compulsória em cursos regulares de estabelecimentos públicos e particulares de pessoas portadoras de deficiência capazes de se integrarem no sistema regular de ensino".

A inclusão de crianças surdas no ensino regular vem sendo discutida pelos educadores. Para que ela aconteça apropriadamente, é necessária uma adaptação do ambiente escolar, isto inclui a preparação dos funcionários da instituição escolar, o pessoal da administração e principalmente a do educador, a adequação das salas de aula, afinal os surdos também têm direito à educação e querem e precisam ter sucesso nela e obviamente seu ingresso no mercado de trabalho.

A inclusão de alunos surdos se apresenta como um fato novo para a maioria dos professores e profissionais da educação e surge como um enorme desafio para todos da área escolar, pois, uma escola inclusiva deve oferecer ao aluno possibilidades reais de aprendizagem, caso isso não aconteça, a inclusão será insatisfatória e precária.

A inclusão do deficiente auditivo no ensino regular tem gerado debates quanto à desigualdade linguística. Muitos estudiosos alegam que o aluno surdo não compartilha uma língua comum com os seus colegas e professores e por isso não há igualdade linguística na sala, e com isso, o aluno surdo fica sem garantia de acesso aos conhecimentos. Assim, em razão da defasagem auditiva, tais sujeitos enfrentam dificuldades para entrar em contato com a língua do grupo social em que estão inseridos (GÓES, 1996).

Sanches e Teodoro (2006) afirmam:

\begin{abstract}
A educação inclusiva não significa educação com representação e baixas expectativas em relação aos alunos, mas sim a compreensão do papel importante das situações estimulantes, com graus de dificuldade e complexidade que confrontem os professores e os alunos com aprendizagens significativas, autênticos desafios à criatividade e à ruptura das idéias feitas. Infelizmente a escola ainda faz parte de uma sociedade preconceituosa e excludente, por isso os estudiosos afirmam que é necessário a elaboração de propostas diferenciadas de aprendizagem e a formação de uma equipe especializada para dar suporte a escola e professores. (SANCHES e TEODORO (2006, p. 73)
\end{abstract}

O aluno surdo deve frequentar o sistema regular de ensino, afinal ele é um cidadão com os mesmos direitos dos cidadãos que se julgam normais. No ensino regular ele fará o uso da leitura orofacial, exercitará assim a expressão oral e a escrita.

Para a integração do aluno surdo em classe comum Brito (1993) recomenda que:

\footnotetext{
A Escola estruture-se quanto aos recursos humanos, físicos e materiais;- o processo ocorra após o período de alfabetização, quando o educando já possui razoável domínio da Língua Portuguesa (falada e/ou escrita). No entanto, de acordo com as condições que ele apresentar, nada impede que a integração ocorra na pré escola ou em qualquer outra série;- a Escola, que vai receber este aluno, tenha conhecimento da sua forma de
} 
comunicação;- a Escola só o recebe para inclusão em classe comum, quando houver garantia de complementação curricular sem Sala de Recursos, professores itinerantes ou intérprete de LIBRAS;- a Escola organize a classe comum de forma que não tenha mais de 25 alunos,incluindo o integrado; - sua idade cronológica seja compatível com a média do grupo da classe comum que irá freqüentar;- a Escola comum mantenha um trabalho sistemático visando a participação da família no processo educacional. (BRITO, 1993 p.15 e 16)

As escolas que receberem o aluno com surdez precisam adotar o modelo bilíngue de educação, para que ele tenha a oportunidade de adotar a língua de sinais como sua primeira língua, isso possibilitará um melhor desenvolvimento linguístico do surdo e contribuirá significativamente no seu desenvolvimento afetivo, social e cognitivo.

Os educadores do ensino regular devem proporcionar situações de interação entre o aluno surdo e os demais alunos, para que isso desperte sua motivação. A escola deve organizarse de um modo que professores e alunos compartilhem o conhecimento. Os alunos surdos possuem uma linguagem riquíssima que deve ser compartilhada com os ouvintes.

Diante do exposto, é notório que a inclusão do aluno com deficiência auditiva no ensino regular é determinante para o desenvolvimento da aprendizagem e como partícipe de um contexto sociocultural. Mas para que isso ocorra, é urgente e necessário o compromisso da comunidade escolar em adequar as metodologias para atender este aluno, criando alternativas de fazê-lo ingressar e permanecer no ambiente escolar de forma participativa, comprometido com o seu desenvolvimento escolar sem nunca deixá-lo de perceber diferente como é cada aluno deste ambiente diferenciado de valores que a escola retrata, enquanto fatia de uma sociedade inclusiva a qual pretendemos formar.

\section{O Papel e a Importância do Intérprete de Libras}

O papel do intérprete é realizar de forma clara a interpretação da língua falada para a língua de sinais, seguindo fielmente algumas regras: ser neutro, não opinar, ser discreto, não misturar o pessoal com o profissional, e ser fiel no sentido de interpretar só o que foi dito.

Interpretar envolve um ato cognitivo linguístico, é um procedimento, e o intérprete estará diante de pessoas que se comunicam usando línguas diferentes, e deve está envolvido por completo na comunicação e pode dominar o objeto e o produto da explicação.

O intérprete transforma a "língua fonte" para a "língua alvo" de forma clara e objetiva aproximando o máximo possível da informação dada pela fonte. Ao interpretar para o surdo 
precisa formular todas as informações, que estão sendo abordadas, ele terá que preparar um planejamento, ou seja, ira organizar os conhecimentos para poder transmiti-lo, tendo em vista os diferentes tipos de discursos torna-se necessário que o intérprete procure possibilidades, elementos linguísticos e referenciais sobre o que é usado no momento e que facilite o surdo nos textos escritos ou falados, portanto é utilizado o planejamento linguístico do locutor.

Segundo Quadros (2003:79):

\begin{abstract}
O foco está no vocabulário e nas frases. Decisões sobre o significado estão baseadas nas palavras. Pensa-se no intérprete como um reprodutor de textos, sinais, palavras sentenças, quando na verdade sabemos que somente sinais, palavras e sentenças não são suficientes para que o surdo construa sua concepção referente ao discurso. (QUADROS, 2003, p.79)
\end{abstract}

A fala de Quadros, garante o fato de na maioria das vezes o tradução ser interrompida pelo surdo por não entender o que lhe é passado ou seja sem conhecimento linguístico, é de grande importância que o intérprete tenha noção sobre o assunto para facilitar a compreensão do surdo durante a interpretação ou seja o intérprete entra em contato com o locutor para tirar suas dúvidas sobre o assunto a ser tratado, dando assim condições ao profissional de planejar sua interpretação.

No contexto de sala de aula o intérprete precisa poder negociar conteúdos com o professor, revelar suas dúvidas, as questões do aprendiz e por vezes mediar a relação com o aluno, para que o conhecimento que se almeja seja construído. O incômodo do professor frente à presença do intérprete pode levá-lo a ignorar o aluno surdo, atribuindo ao intérprete o sucesso ou insucesso desse aluno (LACERDA, 2002, p. 123).

Destaca-se, com base neste na fala de Lacerda, que o responsável pelo conhecimento é o professor, o intérprete organiza dentro do seu planejamento estratégias linguísticas e referenciais, deste modo a organização linguística depende das explicações disponibilizadas ao intérprete, tendo muito cuidado para não mudar o sentido do discurso, e no caso de dúvidas do surdo sempre interagir com o professor de forma clara.

Ainda de acordo com Quadros, (2003:73):

Traduzir um texto em uma língua falada para uma língua sinalizada ou vice-versa é traduzir um texto vivo, uma língua viva. Acima de tudo deve haver um conhecimento coloquial da língua para dar ao texto fluidez e naturalidade ou solenidade e sobriedade se ele for desse jeito. (QUADROS, 2003, p.73)

Sendo assim, o que explicita Quadros é que o intérprete necessita ter as competências para que haja sucesso na sua formação, pois sua prática é de interpretar várias áreas do 
conhecimento. No Brasil, o intérprete é o profissional que domina a Língua Brasileira de Sinais e a Língua Portuguesa, ele também pode dominar outros idiomas. O intérprete necessita ter qualificação especifica para atuar como tal, e formação especifica na área de atuação como, por exemplo, na área da educação.

Existem alguns equívocos sobre o intérprete: Os professores de surdos não são necessariamente intérpretes da língua brasileira de sinais, cada um exerce seu papel e sua função que são diferentes. Não é porque o professor utiliza muito bem a língua brasileira de sinais, que ele é um intérprete, o papel do professor esta relacionado ao ensino e ao processo interativo social, cultural, e linguístico, já o intérprete é o mediador no processo comunicativo das pessoas que não dominam a mesma língua, da mesma forma do professor as pessoas ouvintes que dominam a língua de sinais não necessariamente estão aptas a exercer a função de intérprete de língua de sinais. O que assegura uma pessoa ser um excelente profissional intérprete alem de ser bilíngüe, ou seja, dominar duas línguas, é o fato de está sempre buscando qualificação.

O intérprete educacional é o profissional que atua como intérprete e educador, porém dentro da sala de aula os alunos e professores acabam confundindo o seu papel e sobrecarregando dentro do processo educacional. As crianças da educação infantil e ensino fundamental dos anos iniciais têm muita dificuldade em diferenciar o professor e o intérprete, sendo que uma coisa não tem nada haver com a outra e para facilitar essas dificuldades foi criado um código de ética especifico para o intérprete de língua de sinais que atua na educação.

Uma pessoa só poderá ser contratada como intérprete e não como professor, caso seja requerido um professor que domine língua de sinais, então esse será contratado para tal. É antiético exigir que o intérprete assuma funções como, tutoriar os alunos e etc... O intérprete é apenas um elemento que garante a acessibilidade, ele pode atuar na educação infantil, na educação fundamental, no ensino médio, no nível universitário e no nível de pós graduação, cada nível com sua especificidade. No nível inicial as crianças tem dificuldades em entender o papel do intérprete como mediador entre professor e aluno, os adolescentes e adultos conseguem fazer essa diferença.

Esse profissional educador tem duas profissões, a de professor e de intérprete de língua de sinais. Em um turno poderá exercer a função de docente, regendo uma sala de aula, e no outro turno exercer a função de intérprete onde há outro professor mediador. 


\section{O Funcionamento e a Importância das Salas de AEE - Atendimento Educacional Especializado como Suporte para o Aluno Surdo}

A sala do AEE - Atendimento Educacional Especializado funciona no contra turno das escolas, onde são desenvolvidas funções e atividades que contribuem para o aprendizado do aluno.

A sala do AEE é um espaço organizado com materiais didáticos, pedagógicos, equipamentos e profissionais com formação para o atendimento às necessidades educacionais especiais. (ALVES, 2006, p. 14)

Concordando com Alves, é de grande importância a implantação dessas salas especializadas para que possa identificar, efetuar e sistematizar recursos pedagógicos de acessibilidade com o propósito de eliminar barreiras para o envolvimento do aluno no contexto social e educacional. A educação inclusiva começou a se fortalecer, com a chegada de uma equipe especializada realizando atendimento nas escolas.

A partir de 2008 as salas dos recursos começaram a ser montadas e o trabalho educacional especializado se desenvolveu para a formação do estudante. As salas do AEE alem de inclusiva, ajudam a identificar, elaborar e organizar os recursos pedagógicos.

Os alunos acompanhados nas salas de AEE são de escolas municipais, e têm como objetivo dar liberdade para que o aluno com deficiência possa construir seu aprendizado pois a educação é um direito de todos e para que haja a inclusão o aluno com necessidades especiais tem que estar matriculado e frequentando o ensino regular.

O planejamento do AEE é implementado e produzido juntamente com professores que lecionam aulas em Libras, docente de classe comum e de língua portuguesa para pessoa com surdez. Inicia-se o planejamento em conjunto com a fixação do conteúdo curricular, fazendo com que o professor se aprofunde nos assuntos a serem ministrados em sala de aula, logo após os professores preparam o plano de ensino e o caderno de estudos dos discentes, com conteúdos inter-relacionados. Em seguida os professores escolhem os recursos didáticos para o AEE em Libras e em Língua Portuguesa, respeitando as diferenças entre os alunos surdos, os profissionais que trabalham com eles fazem observações nos seguintes aspectos: sociabilidade, motricidade, afetividades, talentos e etc., registrando assim o desempenho e as observações no relatório com todos os dados colhidos ao longo do processo.

Sobre as salas de AEE e o ensino da linguagem, Damázio (2005) acrescenta que: 
$\mathrm{O}$ atendimento especializado educacional se dar em três momentos, que são o ensino de língua de sinais, o ensino em língua de sinais, e o ensino de língua portuguesa, esses momentos devem acontecer de forma sistemática pois se isso não acontecer, prejudicara o desenvolvimento do aluno. (DAMÁZIO, 2005 p. 117)

No AEE em Libras na escola comum, há explicações sobre o assunto estudado em sala de aula diariamente, o professor que ministra aulas em Libras deve ser qualificado, favorecendo ao aluno com surdez a compreensão dos conteúdos aplicados em sala de aula, o professor surdo para a língua de sinais oferece mais vantagens para o aluno pois favorece a compreensão dos conteúdos exigidos, as imagens visuais é de fundamental importância para a compreensão do conteúdo curricular em língua de sinais e outros recursos como teatro por exemplo, todos os recursos utilizados em sala de aula comum pode ser utilizado na sala de atendimento especializado em Libras.

O AEE para o ensino de Libras estabelece o segundo momento didático pedagógico para os alunos com surdez inseridos na escola comum, esse atendimento é realizado no contra turno escolar, inicia-se com um diagnóstico prévio para saber em qual nível e as dificuldades que esse aluno se encontra, se ele tem um bom ou lento desenvolvimento, esse trabalho é desenvolvido por um professor ou instrutor preferencialmente surdo, de acordo com o nível de cada aluno na língua de sinais, o planejamento deve ser elaborado de acordo com desenvolvimento e diagnóstico que o aluno tem através da língua de sinais, e a partir disso traçar uma metodologia para que ele possa ter um conhecimento técnico e científico, e depois se aprofundar na língua de sinais para ter conhecimento acadêmico em Libras. O professor ou instrutor pesquisam em livros, internet ou fazem entrevistas com adultos surdos, para se certificarem da existência ou criam termos científicos em Libras, esses termos são guardados em um caderno de registro de língua de sinais, onde o aluno surdo tem todo acesso a gravura e ao sinal para facilitar seu entendimento, como se fosse um dicionário particular.

O AEE para o ensino de Língua Portuguesa, é realizado na sala de recursos multifuncionais no contra turno, esse trabalho é desenvolvido por um professor preferencialmente com graduação em Língua Portuguesa e que esteja preparado a fazer a diferença no ensino do português para os alunos com surdez. A intenção do AEE é aperfeiçoar a competência gramatical ou linguística nas pessoas surdas, para com isso serem capazes de realizar sequências linguísticas.

Um dos recursos imprescindíveis para a sala do AEE é a riqueza de materiais visuais (imagéticos), a equipe de professores de Português, de Libras e os da sala comum analisam o desenvolvimento dos alunos com surdez em relação ao conhecimento da língua portuguesa e a 
partir desse momento a docente, focaliza os estudos de como são atribuídos e como se organiza nas frases e textos dando assim subsídios ao aluno levando o mesmo a construir um conhecimento adquirido naturalmente pelos alunos ouvintes.

$\mathrm{Na}$ educação infantil inicia-se um processo de sentindo das palavras de forma contextualizada, intensificando-se na alfabetização dando continuidade no ensino superior, essa mesma equipe de professores organizam os termos específicos em um glossário ilustrado e após esse trabalho são feitos estudos, das diferentes formas e significados que as palavras podem assumir em diferentes contextos.

\section{Conclusão}

Ao longo da construção deste trabalho, muitos pontos merecem destaque, mas um ponto que não foi destacado é a importância que deveria ter a inclusão do aluno surdo também nas escolas privadas. A inclusão deve acontecer em todas as esferas de governo, assim como na educação particular. O Decreto $N^{\circ} 5.626$ de 2005 salienta em seu $\S 2^{\circ}$ que as instituições privadas, assim como as públicas buscarão medidas para assegurar aos alunos surdos ou com deficiência auditiva o acesso à comunicação, à informação e à educação.

Com clareza pode-se concluir que por meio de pesquisas bibliográficas realizadas na área da inclusão escolar para a educação especial dos surdos, constatou-se que a Educação Inclusiva é desafiador para todos os profissionais envolvidos no processo educativo e para a sociedade em geral, pois a inclusão é um dos princípios fundamentais para transformar o indivíduo, independente de qual seja a deficiência.

Concluiu-se que a educação deve ser pautada na cooperação, na criatividade, na reflexão crítica, na solidariedade e preparada para atender a uma diversidade maior de alunos. Assim como observou-se que as leis relacionadas às pessoas com deficiência auditiva surgiram para atender seu público de modo a não excluí-los de nenhum processo educativo, mas comparando com a realidade da sociedade atual, a legislação que inclui, o faz parcialmente e sendo assim, não possibilita a emancipação dos sujeitos.

Que as salas de AEE - Atendimento Educacional Especializados são grandes aliadas do ensino e da aprendizagem, assim como o intérprete de Libras, um profissional que deve fazer a tradução com fidelidade para respeitar a identidade da pessoa surda. 
Evidenciou-se que as instituições de ensino devem adotar metodologias diferenciadas para atender as diferenças e buscar o reconhecimento do outro independente de suas condições sociais, intelectuais ou físicas. As escolas devem passar por uma adequação, para que se tornem acessíveis a todos, com a qualificação dos profissionais envolvidos, principalmente a dos educadores e a modificação da estrutura escolar.

Por fim, é urgente que as escolas tornem-se de todos. Escolas onde seus estudantes prendam a se comunicar e viver dentro de seu espaço sentindo-se integrada, e que os professores sejam atuantes no papel mediador. Uma escola onde a igualdade e os direitos sejam respeitados.

\section{Referências}

ALVES, Denise de Oliveira. Sala de recursos Multifuncionais: espaços para o atendimento educacional especializado. Ministério da educação Secretaria de educação especial. Brasília, 2006.

ARANHA, Ma Salete Fabio. Educação inclusiva: v. 4 : a família / coordenação geral SEESP/MEC; Brasília : Ministério da Educação, Secretaria de Educação Especial, 2004. 17 p.

BRASIL. Constituição da República Federativa do Brasil. Brasília, DF: Senado, 1988.

BRASIL. DECRETO $\mathbf{N}^{\mathbf{5}} \mathbf{5 . 6 2 6}$, DE 22 DE DEZEMBRO DE 2005.http://legislacao.planalto.gov.br.

BRASIL. Lei de Diretrizes e Bases da Educação Nacional, Lei n. 9394/96. Estabelece as diretrizes e bases da educação nacional.

BRASIL. Lei n.10.436, de 24 de abril de 2002. Dispõe sobre a Língua Brasileira de Sinais LIBRAS-e dá outras providências. Disponível em: http://www.planalto.gov.br.

BRASIL. Ministério da Educação. Secretaria de Educação Especial. Diretrizes Curriculares Nacionais para a Educação Especial, 1998.

BRASIL. Lei $\mathbf{N}^{\mathbf{0}} \mathbf{. 7 . 8 5 3}$, de 24 de outubro de 1989.Dispõe sobre o apoio às pessoas com deficiência e sua integração social. Brasília.

BRITO L.F. Integração social \& Educação de surdos. Rio de Janeiro: Babel; 1993.

BUENO, José Geraldo Silveira. Educação especial brasileira: integração/segregação do aluno diferente. São Paulo: EDUC, 1998. 
DAMAZIO, Mirlene Ferreira de Marcedo, Educação escolar com pessoas com surdez: Uma proposta inclusiva. (2005 p. 117)

GÓES, Maria Cecília Rafael de. Linguagem, surdez e educação. Campinas, 1996.

GOKHALE, S.D. A Família Desaparecerá? In Revista Debates Sociais no 30, ano XVI. Rio de Janeiro, CBSSIS, 1980.

LACERDA, Cristina B. F. de. O intérprete educacional de língua de sinais no ensino fundamental: Refletindo sobre limites e possibilidades, IN: LODI, Ana Claudia. Et AL Letramento e minorias. Porto Alegre: Mediação, 2002.

PEREIRA, Cleide Lucia. Educação Inclusiva: uma breve reflexão sobre avanços no Brasil após a Declaração de Salamanca. Revista da Católica, Uberlândia, v. 1, n. 2, p. 265-274, 2009 - catolicaonline.com.br/revistadacatolica

QUADROS, Ronice Muller de. $O$ tradutor e intérprete de línguas brasileiras de sinais e língua portuguesa. Brasilia: MEC; SEESP; programa nacional de apoio a educação de surdos, 2003.

SANCHES, Isabel; TEODORO, Antônio. Da integração à inclusão escolar cruzando perspectivas e conceitos. Revista Lusófona de Educação, Lisboa, PT, v.8, p. 63-83, 2006.

Como citar este artigo (Formato ABNT):

SANTOS, Maria K. C. dos. MENEZES, Aurelania M. de C. Educação Especial na Perspectiva da Educação Inclusiva para Surdos. Id on Line Revista Multidisciplinar e de Psicologia, 2017, vol.11, n.38, p. 493-506. ISSN: 1981-1179.

Recebido: 01.10.2017

Aceito: 03.11.2017 